\title{
Bentonite diminishes DON-induced changes in bone development in mink dams
}

\author{
Ewa Tomaszewska ${ }^{1}$, Siemowit Muszyński $^{2}$, Piotr Dobrowolski ${ }^{3}$, \\ Krzysztof Kostro ${ }^{4}$, Iwona Taszkun ${ }^{5}$, Andrzej Żmuda ${ }^{4}$, \\ Tomasz Blicharski ${ }^{6}$, Paweł Kędzia \\ ${ }^{1}$ Department of Animal Physiology, Faculty of Veterinary Medicine, \\ ${ }^{2}$ Department of Physics, Faculty of Production Engineering, \\ University of Life Sciences, 20-950 Lublin, Poland \\ ${ }^{3}$ Department of Comparative Anatomy and Anthropology, \\ Maria Curie-Skłodowska University, 20-950 Lublin, Poland \\ ${ }^{4}$ Department of Epizootiology and Clinic of Infectious Diseases, Faculty of Veterinary Medicine, \\ ${ }^{5}$ Sub-department of Clinical Diagnostics and Veterinary Dermatology, \\ Department and Clinic of Internal Medicine, Faculty of Veterinary Medicine, \\ University of Life Sciences, 20-950 Lublin, Poland \\ ${ }^{6}$ Chair and Department of Rehabilitation and Orthopaedics, \\ Medical University in Lublin, 20-090 Lublin, Poland \\ ${ }^{7}$ Biomin, 04-217 Warsaw, Poland \\ ewaRST@interia.pl
}

Received: March 9, 2016

Accepted: September 6, 2016

\begin{abstract}
Introduction: The aim of this study was to determine the effect of deoxynivalenol (DON), given alone or with bentonite (which eliminates mycotoxicity) in the diet of mink dams throughout mating, pregnancy, and lactation period to pelt harvesting, on the mechanical properties and geometry of their long bones. Material and Methods: The minks were randomly assigned into two groups: a control group (not supplemented with DON, $\mathrm{n}=15$ ) and a group fed naturally DON-contaminated wheat and divided into three sub-groups (each sub-group $n=15$ ), depending on bentonite dose: $0 \mathrm{M}$ - sub-group fed naturally DONcontaminated wheat at a concentration of $3.7 \mathrm{mg} \mathrm{kg}^{-1}$ alone; $2 \mathrm{M}$ - sub-group fed naturally DON-contaminated wheat at a concentration of $3.7 \mathrm{mg} \mathrm{kg}^{-1}$ and bentonite at a concentration of $2 \mathrm{~kg} 1000 \mathrm{~kg}^{-1} ; 0.5 \mathrm{M}$ - sub-group fed naturally DONcontaminated wheat at a concentration of $3.7 \mathrm{mg} \mathrm{kg}^{-1}$ and bentonite at a concentration of $0.5 \mathrm{~kg} 1000 \mathrm{~kg}^{-1}$. Results: The DON treatment reduced the length of the femur compared to the control group and reduced the bone weight dependently on the amount of bentonite supplementation. However, DON treatment reduced the MRWT and CI of the femur, irrespective of the bentonite supplementation, compared to the control. The total BTD and BMC decreased in all DON-treated groups (irrespective of the bentonite supplementation). Furthermore, the densitometric analysis showed that the main changes in BMD and BMC indicated bone loss in the proximal and distal parts of bone covering the trabecular bone; whereas when bentonite was given at the dose of $2 \mathrm{~kg} 1000 \mathrm{~kg}^{-1}$ an increase in the whole BMD and BMC was observed in the femoral midshaft. Conclusion: Analysis of the geometrical parameters seems to indicate that endosteal resorption was delayed after bentonite supplementation. The addition of bentonite diminished the DON action on bone homeostasis in the mink dams. Thus bentonite could prevent DON-induced bone loss in a dose-dependent manner.
\end{abstract}

Keywords: mink, bone, deoxynivalenol, bentonite, mechanical endurance.

\section{Introduction}

Trichothecenes are a group of mycotoxins produced by Fusarium, Stachybotrys, and other moulds growing on basic commodities used in animal feeds or in the environment (19). Trichothecene contamination of agricultural staples such as wheat, barley, and maize during Fusarium colonisation is a common problem 
linked with the functioning of large-scale farms. Microbiological contamination of feed, which significantly modifies the nutrition of fur animals results from the storage of expired components for too long under disadvantageous conditions (4). When infested feed (seeds, post-extractional middlings) is stored under inappropriate conditions, it promotes the growth of fungi producing mycotoxins that are dangerous to animals (4). Mycotoxins are nonimmunogenic, invulnerable to high temperatures, highly active even at low concentrations, with carcinogenic, mutagenic, teratogenic, and oestrogenic activity. They penetrate into the body mainly via diet, rarely by inhalation or through the skin and conjunctiva; however, mycotoxins are not transferred between individuals (5). They can penetrate the placenta and reach the foetus or are present in mother's milk $(2,3)$. Deoxynivalenol (DON), called vomitoxin, produced by Fusarium culmorum and Fusarium graminearum, is the most serious problem. Its content is the main indicator of feed quality. DON is particularly stable in the environment, posing a grave health problem for both humans and animals (19). DON inhibits protein synthesis and generates many toxic effects, such as anorexia, emesis, diarrhoea, anaemia, haemorrhage, weight loss, nervous disorders, skin toxicity, and bone marrow damage (19). Harmful effects of mycotoxins are manifested already at a low level (1 mg kg-1 of cereals). According to the recommendations of the European Union, the DON content must not exceed $1 \mathrm{mg} \mathrm{kg}^{-1}$ in wheat grain and $0.5 \mathrm{mg} \mathrm{kg}^{-1}$ in flour. In contrast, the content of DON in wheat grain or triticale is ca. $30 \mathrm{mg} \mathrm{kg}^{-1}(6)$. It is known that the sensitivity of different species of animals to DON varies. Ruminants and poultry tolerate up to $20 \mathrm{ppm}\left(20 \mathrm{mg} \mathrm{kg}^{-1}\right)$ of DON in feed, whereas 1-2 ppm (1-2 $\left.\mathrm{mg} \mathrm{kg}^{-1}\right)$ causes toxicity in pigs (19). Some effects caused by DON seem to be a consequence of absorption thereof from the alimentary tract and its general action in the organism (15). Moreover, our earlier studies proved that there is an axis linking the gut and bones (24). DON was also found to disturb calcium homeostasis. Rats treated with this mycotoxin (10 mg kg-1 b.w. within seven days) manifested a decrease in intestinal calcium absorption and hypocalcaemia with concomitant impairment in vitamin D metabolism (22). However, there are no data about the influence of long-term DON treatment on bone metabolism in mink dams.

Different methods are employed to inhibit the growth of toxin-producing fungi in feed. Modern methods of conservation that can be used in production of food with a low processing level comprise ultrasounds, high-pressure techniques, radiation treatment, pulsed electric field techniques, and modified atmosphere packaging (18). For many years, investigations have been performed to assess the application of specific enzymes in animal production which to eliminate the toxicity of trichothecenes, zearalenone, and ochratoxin by changing the spatial structure of the toxins, as well as their use as bioactive compounds added to feed. Such transformation of mycotoxins in their presence leads to production of non-toxic and environmentally safe metabolites. Moreover, bentonite, a natural and biologically active soil component, has recently been authorised as a technological feed additive without any restriction (11). This product was registered under the European Commission Implementing Regulation No. 1060/2013 and its application involves inhibition of the growth of toxin-producing fungi in feed of minks.

The lack of knowledge of the influence of dietary DON-treatment on mineralisation and functional adaptation in the mink skeleton during the whole period of production on the farm has motivated us to determine the influence of dietary administration of DON on bone tissue properties.

The aim of this study was to determine the effect of DON, given alone or with bentonite (which eliminates mycotoxicity) in the diet of mink dams throughout the period of mating, pregnancy, and lactation to pelt harvesting, on the mechanical properties and geometry of their long bones.

\section{Material and Methods}

Animal breeding and experimental design. The study was carried out on a mink-breeding farm located in south Poland. Sixty clinically healthy multiparous minks (Neovison vison) of the standard dark brown type were used. They were held individually in separate cages under standard breeding/farming conditions and the natural photoperiod with free access to fresh water. The animals were fed a well-balanced standard farm diet once a day. The mink dams were mated in March; next, after the delivery (May, June), the lactated dams were kept with their kits until weaning (after approximately two months in September), after which they were held until pelt harvesting performed in December/January. In accordance with the farm procedures and the national Polish legislation, all dams were euthanised by carbon monoxide inhalation at pelt harvesting and skinned carcasses were delivered to the laboratory $(1,12)$.

Bentonite. Bentonite (Mycofix ${ }^{\circledR}$, Biomin, Warsaw, Poland) was used as a technological feed additive (11).

Diet. After mating, the minks were randomly assigned into two groups: a control group $(n=15$; not supplemented) and a group fed naturally DONcontaminated wheat. The group was divided into three sub-groups (each sub-group $\mathrm{n}=15$ ) according to bentonite dose: $0 \mathrm{M}$ - sub-group fed naturally DONcontaminated wheat at a concentration of $3.7 \mathrm{mg} \mathrm{kg}^{-1}$; $2 \mathrm{M}$ - sub-group fed naturally DON-contaminated wheat at a concentration of $3.7 \mathrm{mg} \mathrm{kg}^{-1}$ and bentonite at a concentration of $2 \mathrm{~kg} 1000 \mathrm{~kg}^{-1}(0.2 \%) ; 0.5 \mathrm{M}$ - sub- 
group fed naturally DON-contaminated wheat at a concentration of $3.7 \mathrm{mg} \mathrm{kg}^{-1}$ and bentonite at a concentration of $0.5 \mathrm{~kg} 1000 \mathrm{~kg}^{-1}(0.05 \%)$. The basal diet fed throughout the study included cereal, beef liver, raw poultry by-products, and fish. This basal diet was given to the control group. The diet administered to the minks from the DON group since day one after mating throughout the gestation (ca. $46 \mathrm{~d}$ ) and lactation period to pelt harvesting included an $8 \%$ addition of naturally DON-contaminated wheat.

Bone analysis. The bone length and weight were measured after removal of soft tissues from the femora. Each bone was wrapped in gauze soaked in isotonic saline and stored at $-25^{\circ} \mathrm{C}$ for further analysis. The mechanical properties of bones were determined after three-hour thawing at room temperature using the three-point bending test. The mechanical properties such as the maximum elastic strength, the ultimate strength, and displacement (x) at the ultimate strength were examined on a Zwick Z010 as described previously $(13,24,25)$. the following bone material properties were also analysed: ultimate bending moment (M), as ultimate force applied to the bone adjusted for the distance between the supports; ultimate bending stress $(\sigma)$, as ultimate force applied to the unit of the bone cross section; strain $(\varepsilon)$, as the ratio between original length and the change in bone length as a result of the ultimate force application (7).

Bone mineral measurement. The measurement of bone tissue density (BTD) for the whole bone was performed with a helium gas pycnometer (AccuPyc 1330; Micromeritics, USA) as described previously $(10,17,26)$.

The measurement of bone mineral density (BMD) and bone mineral content (BMC) was performed for the whole bone (as a total), and separately for the distal (BMDd or BMCd) and proximal (BMDp or BMCp) parts, including both trabecular and cortical bone compartments and the middle section of the midshaft (BMDm or BMCm; containing mainly cortical bone) covering $40 \%$ of the total bone length as a distance between the supports in mechanical testing. This analysis was performed using a Discovery W Hologic X-ray densitometer (Bedford, USA) and APEX 3.0.1 software with a Small Animal Studies option for investigation of bones from various types of animals. Densitometer self-calibration was performed before the measurements using the Hologic Automatic Internal Reference System. An optional Scout scan was available to assist the operator in defining the scan region. The analysis was performed on the scan data using an operator-defined region of interest and numeric results were calculated and displayed. The operator had the capability to adjust the start and end points of the Scout and Measurement scan. The measurements of BMC and BMD were performed using the following parameters: additional calibration with Hologic Rat Step Phantom P/N 010-0758 Rev.004 and resolution 0.5 line pair $/ \mathrm{mm}(1.0 \times 1.0 \mathrm{~mm})$. The region of interest was defined manually after the scout scan.

Moreover, based on the measurements of the horizontal external $(\mathrm{H})$ and internal $(\mathrm{h})$ as well as the vertical external (B) and internal (b) diameters of the mid-diaphyseal cross-section of bone, the mean relative wall thickness (MRWT) and the cross-sectional area (A) were calculated (13). The cortical index (CI) of the bone was also estimated as described previously (24- 26).

Statistical analysis. All results are expressed as means \pm SD (standard deviation). To detect any significant difference between the groups, one-way analysis of variance (ANOVA) followed by Tukey's multiple comparison test were carried out. For all comparisons, the probability level of $\mathrm{P}<0.05$ was considered as statistically significant. All statistical analyses were carried out by means of Statistica 12 software (StatSoft, Inc., USA).

\section{Results}

Body weight. Reduction of final mean body weight was observed in the group treated only with DON, compared to the other groups. On the other hand, the bentonite supplementation to the DON-poisoned mink dams resulted in an increase in the final mean body weight, depending on the dosage used in the diet, compared to the group treated with DON alone (Table 1).

Bone morphology and geometry. When DON was given alone or simultaneously with $0.5 \mathrm{~kg}^{1000 \mathrm{~kg}^{-1}}$ of bentonite added to the diet, a decrease in the bone mass was observed, compared to the other groups (Table 1). Reduction of bone length was observed in the group treated only with DON, compared to the control group. Bentonite supplementation did not influence the length of the femur, irrespective of the bentonite concentration. However, DON treatment reduced MRWT and CI of the femur, irrespective of bentonite supplementation, compared to the controls. The MRWT and CI of the femur did not differ among DON-treated groups. Irrespective of the bentonite action, DON significantly increased all the diameters except $\mathrm{h}$, compared to the control group. A significant increase in h was only observed in group $0 \mathrm{M}$ (Table 1 ).

Bone density and relative bone volume. The total BTD and BMC decreased in all DON-treated groups (irrespective of the bentonite supplementation). The BMD and BMC of the distal and proximal parts of the femur also decreased after the DON treatment (Table 1). In contrast, the BMD of the midshaft increased in mink dams supplemented with bentonite at the dose of $2 \mathrm{~kg} 1000 \mathrm{~kg}^{-1}$ of feed, compared with other DON-supplemented groups. Moreover, the BMC of the midshaft increased in animals supplemented with bentonite at the dose of $2 \mathrm{~kg} 1000 \mathrm{~kg}^{-1}$ of feed, compared with the other groups. In turn, DON given 
alone or with bentonite at the dose of $0.5 \mathrm{~kg} 1000 \mathrm{~kg}^{-1}$ of feed decreased the BMC in the midshaft. Moreover, bentonite given at the lower dose did not prevent BMD loss in all parts of the bone (Table 1).

Bone mechanical properties. DON supplied alone or with bentonite, irrespective of its dose, during the whole pregnancy, lactation, and after weaning until pelt harvesting decreased the maximal elastic strength and ultimate bending stress, compared to the control group (Table 2). When DON was given alone in the diet, a decrease in the ultimate bending moment was observed, compared to the other groups. There were no changes observed in the values of the ultimate strength, displacement, and strain (Table 2).

Table 1. The effect of a diet containing DON on body weight and geometric properties of mink dam femur

\begin{tabular}{|c|c|c|c|c|}
\hline \multirow{2}{*}{ Measured parameter } & \multirow{2}{*}{ Control } & \multicolumn{3}{|c|}{ DON $3.7 \mathrm{mg} \mathrm{kg}^{-1}$} \\
\hline & & $0 \mathrm{M}$ & $2 \mathrm{M}$ & $0.5 \mathrm{M}$ \\
\hline Body weight (g) & $1720 \pm 212^{\mathrm{a}}$ & $1477 \pm 189^{\mathrm{b}}$ & $1952 \pm 198^{c}$ & $1737 \pm 210^{\mathrm{a}}$ \\
\hline Bone mass (g) & $1.97 \pm 0.11^{\mathrm{a}}$ & $1.65 \pm 0.11^{\mathrm{b}}$ & $2.06 \pm 0.11^{\mathrm{a}}$ & $1.66 \pm 0.23^{\mathrm{b}}$ \\
\hline Bone length (mm) & $51.1 \pm 1.6^{\mathrm{ac}}$ & $48.3 \pm 1.3^{\mathrm{b}}$ & $49.7 \pm 2.3^{\mathrm{ab}}$ & $50.3 \pm 1.7^{\mathrm{c}}$ \\
\hline Horizontal internal diameter $\mathrm{h}(\mathrm{mm})$ & $1.82 \pm 0.07^{\mathrm{a}}$ & $1.97 \pm 0.03^{b}$ & $1.91 \pm 0.04^{\mathrm{a}}$ & $1.88 \pm 0.02^{\mathrm{a}}$ \\
\hline Horizontal external diameter $\mathrm{H}(\mathrm{mm})$ & $4.28 \pm 0.07^{\mathrm{a}}$ & $4.55 \pm 0.05^{\mathrm{b}}$ & $4.67 \pm 0.05^{b}$ & $4.63 \pm 0.04^{b}$ \\
\hline Vertical internal diameter $\mathrm{b}(\mathrm{mm})$ & $1.41 \pm 0.03^{\mathrm{a}}$ & $1.69 \pm 0.05^{\mathrm{b}}$ & $1.72 \pm 0.05^{\mathrm{b}}$ & $1.66 \pm 0.03^{b}$ \\
\hline Vertical external diameter B (mm) & $3.45 \pm 0.09^{\mathrm{a}}$ & $3.95 \pm 0.12^{\mathrm{b}}$ & $3.93 \pm 0.11^{\mathrm{b}}$ & $3.86 \pm 0.19^{b}$ \\
\hline Cortical cross section area $\left(\mathrm{mm}^{2}\right)$ & $10.5 \pm 0.4$ & $11.5 \pm 1.4$ & $11.8 \pm 1.2$ & $11.6 \pm 1.42$ \\
\hline Mean relative wall thickness MRWT & $2.51 \pm 0.75^{\mathrm{a}}$ & $1.39 \pm 0.41^{\mathrm{b}}$ & $1.41 \pm 0.21^{\mathrm{b}}$ & $1.46 \pm 0.25^{\mathrm{b}}$ \\
\hline Cortical index CI & $69.2 \pm 6.0^{\mathrm{a}}$ & $57.1 \pm 6.2^{\mathrm{b}}$ & $57.7 \pm 4.5^{b}$ & $58.5 \pm 4.2^{b}$ \\
\hline Total bone tissue density $\left(\mathrm{g} / \mathrm{cm}^{3}\right)$ & $2.16 \pm 0.05^{\mathrm{a}}$ & $2.06 \pm 0.01^{\mathrm{b}}$ & $2.07 \pm 0.01^{\mathrm{b}}$ & $2.07 \pm 0.03^{b}$ \\
\hline Total bone mineral density $\left(\mathrm{g} / \mathrm{cm}^{2}\right)$ & $0.112 \pm 0.005^{\mathrm{a}}$ & $0.108 \pm 0.002^{\mathrm{a}}$ & $0.123 \pm 0.001^{\mathrm{b}}$ & $0.075 \pm 0.001^{\mathrm{c}}$ \\
\hline Total bone mineral content $(\mathrm{g})$ & $0.189 \pm 0.015^{\mathrm{a}}$ & $0.087 \pm 0.048^{\mathrm{b}}$ & $0.140 \pm 0.005^{\mathrm{c}}$ & $0.075 \pm 0.002^{\mathrm{b}}$ \\
\hline \multicolumn{5}{|l|}{ Proximal part } \\
\hline Bone mineral density $\left(\mathrm{g} / \mathrm{cm}^{2}\right)$ & $0.114 \pm 0.003^{\mathrm{a}}$ & $0.091 \pm 0.001^{\mathrm{b}}$ & $0.104 \pm 0.001^{\mathrm{c}}$ & $0.073 \pm 0.001^{\mathrm{d}}$ \\
\hline Bone mineral content $(\mathrm{g})$ & $0.072 \pm 0.004^{\mathrm{a}}$ & $0.006 \pm 0.002^{\mathrm{b}}$ & $0.016 \pm 0.002^{\mathrm{c}}$ & $0.025 \pm 0.001^{\mathrm{d}}$ \\
\hline \multicolumn{5}{|l|}{ Midshaft } \\
\hline Bone mineral density $\left(\mathrm{g} / \mathrm{cm}^{2}\right)$ & $0.108 \pm 0.009^{\mathrm{ab}}$ & $0.103 \pm 0.021^{\mathrm{a}}$ & $0.125 \pm 0.001^{\mathrm{b}}$ & $0.069 \pm 0.001^{\mathrm{c}}$ \\
\hline Bone mineral content $(\mathrm{g})$ & $0.075 \pm 0.004^{\mathrm{a}}$ & $0.050 \pm 0.003^{b}$ & $0.082 \pm 0.002^{\mathrm{c}}$ & $0.031 \pm 0.002^{\mathrm{d}}$ \\
\hline \multicolumn{5}{|l|}{ Distal part } \\
\hline Bone mineral density $\left(\mathrm{g} / \mathrm{cm}^{2}\right)$ & $0.122 \pm 0.003^{\mathrm{a}}$ & $0.101 \pm 0.002^{\mathrm{b}}$ & $0.092 \pm 0.001^{\mathrm{c}}$ & $0.089 \pm 0.003^{c}$ \\
\hline Bone mineral content $(\mathrm{g})$ & $0.073 \pm 0.002^{\mathrm{a}}$ & $0.017 \pm 0.001^{\mathrm{b}}$ & $0.029 \pm 0.002^{\mathrm{c}}$ & $0.017 \pm 0.002^{\mathrm{b}}$ \\
\hline
\end{tabular}

Data given are mean $\pm \mathrm{SD},{ }^{\mathrm{a}, \mathrm{b}, \mathrm{c}}-\mathrm{P}<0.05 ; 0 \mathrm{M}$ - group fed wheat contaminated naturally with DON (n $\left.=15\right) ; 2 \mathrm{M}-$ group fed wheat naturally contaminated with DON and an addition of bentonite at the concentration of $2 \mathrm{~kg} 1000 \mathrm{~kg}^{-1} ; 0.5 \mathrm{M}-\mathrm{group}$ fed wheat naturally contaminated with DON and an addition of bentonite at the concentration of $0.5 \mathrm{~kg} 1000 \mathrm{~kg}^{-1}$

Table 2. The effect of a diet containing DON on mechanical and material properties of mink dam femur

\begin{tabular}{lllll}
\hline \multirow{2}{*}{ Measured parameter } & \multirow{2}{*}{ Control } & \multicolumn{2}{c}{ DON 3.7 $\mathrm{mg} \mathrm{kg}^{-1}$} \\
\cline { 3 - 5 } & & $0 \mathrm{M}$ & $2 \mathrm{M}$ & $0.5 \mathrm{M}$ \\
\hline Maximum elastic strength (N) & $192 \pm 7^{\mathrm{a}}$ & $134 \pm 21^{\mathrm{b}}$ & $145 \pm 23^{\mathrm{b}}$ & $135 \pm 13^{\mathrm{b}}$ \\
Ultimate strength (N) & $231 \pm 14$ & $213 \pm 18$ & $227 \pm 27$ & $216 \pm 36$ \\
Displacement x (mm) & $1.10 \pm 0.17$ & $0.81 \pm 0.14$ & $0.88 \pm 0.13$ & $0.93 \pm 0.22$ \\
Strain $\varepsilon(--)$ & $0.053 \pm 0.008$ & $0.050 \pm 0.010$ & $0.053 \pm 0.012$ & $0.54 \pm 0.015$ \\
Ultimate bending moment M (N.mm) & $1180 \pm 75^{\mathrm{a}}$ & $1039 \pm 92^{\mathrm{b}}$ & $1123 \pm 116^{\mathrm{a}}$ & $1091 \pm 205^{\mathrm{a}}$ \\
Ultimate bending stress $\sigma\left(\mathrm{N} / \mathrm{mm}^{2}\right)$ & $158 \pm 11^{\mathrm{a}}$ & $105 \pm 7^{\mathrm{b}}$ & $117 \pm 15^{\mathrm{b}}$ & $116 \pm 18^{\mathrm{b}}$ \\
\hline
\end{tabular}

Data given are mean $\pm \mathrm{SD},{ }^{\mathrm{a}, \mathrm{b}}-\mathrm{P}<0.05$; abbreviations as in the Table 1 


\section{Discussion}

There is little data on the effects of trichothecenes on mammalian bone development and homeostasis, although a statistically significant link has been established between cereal contamination by some species of fungi and incidence of skeletal malformations. Avian tibial chondrodysplasia induced by mycotoxins has been reported (14). Moreover, contamination of food with mycotoxins has been suggested as a causal agent of Kashin-Beck disease in a human endemic osteoarticular condition (8).

Even less information is available about the effects of mycotoxin poisoning on bone metabolism in mink. In this preliminary report, we have studied the inhibitory effects of DON when administered via diet to mink for a long period of time. This experimental procedure reflected the effects of chronic ingestion of the mycotoxin. The choice of our experimental procedure was intended to expose the dams to the mycotoxin during a typical fur-animal production cycle in farms.

In our study, a decrease in the body weight and bone mass was observed in minks fed DONcontaminated feed. Moreover, the measurements of total BMD, BTD, and BMC suggested that the DON treatment influenced the degree of bone mineralisation. When DON was administered alone, reduction of the bone length was observed. Furthermore, the DEXA densitometry analysis showed that the main changes in $\mathrm{BMD}$ and BMC indicated bone loss in the proximal and distal parts of bone covering the trabecular bone. A decrease in the midshaft was also observed, but to a lesser extent, indicating that the loss of compact bone was lower. Additionally, there were significant changes in geometry. This was probably an additional cause of the reduced mechanical endurance of the femur in mink dams, as indicated by the reduction of the maximum elastic strength. Moreover, the bone material properties were altered. The changes observed suggest that DON treatment influences the mineral, probably calcium, homeostasis.

It is known that a decrease in intestinal calcium absorption and hypocalcaemia with concomitant impairment in vitamin $\mathrm{D}$ metabolism occur in DON poisoning (8). At the $3.5 \mathrm{ppm}$ (3.5 mg kg-1) DON concentration, increased liver weight and a decreased concentration of serum protein and albumin, as well as serum and phosphorus were observed in pigs (19). Other studies also suggest that DON treatment alters the immune status, because DON is a clinically potent immunomodulator, an inhibitor of protein synthesis, and it increases susceptibility to infection. Augmentation of the delay in immune responses can occur with moderate ( 1 to $5 \mathrm{mg} \mathrm{kg}^{-1}$ ) to higher than $5 \mathrm{mg} \mathrm{kg}^{-1}$ concentrations of DON (20). It is not known whether the immune status in bone was also changed, which in turn could result in severe resorption. The main role in bone turnover is played by two inflammatory cytokines TNF- $\alpha$ and IL-1 $\beta$ or osteoprotegerin as a potent inhibitor of osteoclastogenesis (16).

In addition, our study proved that the increase in the internal diameters could indicate that the process of endosteal resorption could be more intensive than periosteal apposition in the DON poisoning. This disturbance resulted in the alteration of bone geometry, as indicated by the reduced values of MRWT and CI. This could also be a cause of the reduced elastic endurance of the femur, as mentioned above. This reduction indicated that the bone would not be destroyed, but it was more prone to permanent plastic deformation. Moreover, the analysis of the material properties indicated that the femora were destroyed at the lower ultimate bending stress, although the value of the ultimate strength was not changed, but even reduced. As the bending moment is a product of ultimate strength and bone length, the reduction of its value was observed for the shortest bones, noted in the DON-treated group.

The DON treatment causes gastrointestinal symptoms (feed refusal, weight reduction, vomiting, and malabsorption). Decreased feed intake and weight gain occur in castrated male pigs fed diets spiked with $3 \mathrm{ppm}\left(3 \mathrm{mg} \mathrm{kg}^{-1}\right)$ of DON in naturally contaminated maize, but not in pigs fed diets spiked with purified toxin during the first week of exposure. Moreover, no effects were observed at $1 \mathrm{ppm}\left(1 \mathrm{mg} \mathrm{kg}^{-1}\right)(20)$. It was suggested that the differences between naturally contaminated feed ingredients versus feed spiked with purified DON could be attributable to the presence of additional compounds in naturally contaminated grains that contribute additively or synergistically to DON toxicity.

In our study, the addition of bentonite diminished the DON action in a dose-dependent manner. The analysis of the geometric parameters could indicate that endosteal resorption was delayed. There were lower values of internal horizontal perimeter compared to the group treated only with DON, but still these changes were significantly lower compared to the control group. However, there was a lower reduction of MRWT and then lower reduction of maximum elastic strength, compared to the control group. An additional protective mechanism shown by bentonite was its influence on the process of bone mineralisation. The densitometric analysis showed an increase in the whole bone mineral density caused mainly by the increase in the mineral content in the femoral midshaft. However, this protective effect was evident only when bentonite was given at the dose of $2 \mathrm{~kg} 1000 \mathrm{~kg}^{-1}$.

Bentonite is a comprehensive solution against agriculturally burdensome mycotoxins (aflatoxins, trichothecenes, fumonisins, ochratoxin $\mathrm{A}$, and ergot alkaloids). It allows minimising liver or gastrointestinal tract damage caused by the mycotoxins present in the feed. Bentonite binds and immobilises mycotoxins in the gastrointestinal tract of animals, and thus it reduces the toxic bioactivity of fungi. In a wide majority of 
experiments, bentonites show a positive effect on the reduction of symptoms of mycotoxins in pigs, poultry, and ruminants. Nevertheless, there is still insufficient knowledge about the use of bentonite in mink farms (11). Although no typical tolerance studies with bentonites can be found in the literature, the varying bentonite levels $(0.2 \%-10 \%)$ used in a multitude of studies (with poultry, ruminants, and trout) allow safety assessment for the target animals. In a three-week study, Desheng et al. (9) monitored the mineral contents in the bone of chickens for fattening. The $\mathrm{Ca}$, $\mathrm{P}, \mathrm{Cu}, \mathrm{Fe}$, and $\mathrm{Zn}$ levels in bone were not affected by $0.5 \%$ addition of bentonite. However, $0.5 \%$ bentonite already reduced manganese availability in chickens for fattening (11). On the other hand, bentonite improves $\mathrm{Ca}, \mathrm{Mg}$, and P levels in blood (23).

Our study showed that although the level of bentonite in the diet containing DON was much lower $\left(0.5 \mathrm{~kg} 1000 \mathrm{~kg}^{-1} ; 0.05 \%\right)$, it resulted in the reduction of BTD, BMD, and BMC of the femur and reduced its mechanical endurance. However, in the case of BMC, this effect was not observed in the group supplemented with $2.0 \mathrm{~kg} 1000 \mathrm{~kg}^{-1}(0.2 \%)$; in turn, opposite effects were noted. Nonetheless, there is lack of data about the action of bentonite on trace elements in mink dams.

Bone loss (osteopenia and then osteoporosis) is a multifactorial disease with dimensions of genetics, endocrine function, exercise, and nutritional considerations. Calcium status, vitamin D, fluoride, magnesium, and other trace elements are of particular considerations. Several trace elements, particularly copper, manganese, and zinc, are essential for bone metabolism as cofactors for specific enzymes (21). Manganese is needed for optimal bone organic matrix development and bone density sustenance. Animals receiving added manganese show a rise in the manganese content in bone and an increase in phosphatase activity.

In conclusion, this is the first report showing that bentonite could prevent DON-induced bone loss in a dose-dependent manner, suggesting the possible use of bentonite as feed additive for attenuation of mycotoxins in minks. Further research is needed to evaluate the effect of bentonite and DON in regard to various aspects of bone formation in mink dams, including their influence on trace elements content or hormonal status. Moreover, these studies should be conducted especially in the basic herd, where the mean age of mink dams is ca. three years, and they are still reproductively active, which strongly overloads the general metabolism, including bone homeostasis.

Conflict of Interests Statement: The authors declare that there is no conflict of interests regarding the publication of this article.

Financial Disclosure Statement: This research was supported from the funds of the Ministry of Science and Higher Education of the Republic of Poland.
Animal Rights Statement: The experimental procedures used throughout the study were approved by the Local Ethics Committee on Animal Experimentation of University of Life Sciences of Lublin, Poland

\section{References}

1. Animal Protection Act. Journal of Laws of the Republic of Poland No. 111, Item 724.

2. Belmadani A., Tramu G.: Regional selectivity to ochratoxin A, distribution and cytotoxicity in rat brain. Arch Toxicol 1998, 72, 656-662.

3. Blank R., Rolfs J.P., Südekum K.H., Frochlich A.A., Marquardt R.R., Wolfram S.: Effects of chronic ingestion of ochratoxin A on blood vessels and excretion of the mycotoxin in sheep. J Agricult Food Chem 2003, 51, 6899-6905.

4. Bryden W.L.: Mycotoxin contamination of the feed supply chain: implications for animal productivity and feed security. Anim Feed Sci Technol 2012, 173, 134-158.

5. Colakoglu G.: Fungal spore concentrations in the atmosphere at the Anatolia quarter of Istanbul, Turkey. J Basic Microbiol 1996, 36, 155-162.

6. CR 2006/583/EC. Commission Recommendation of 17 August 2006 on the prevention and reduction of Fusarium toxins in cereals and cereal products (Text with EEA relevance). Official J EU L234/35.

7. Crenshaw T.D., Peo Jr E.R, Lewis A.J., Moser B.D.: Bone strength as a trial for assessing mineralization of swine: a critical review of techniques involved. J Anim Sci 1981, 53, 827-835.

8. Debouck C., Haubruge E., Bollaerts P., van Bignoot D., Brostaux Y., Werry A., Rooze M.: Skeletal deformities induced by the intraperitoneal administration of deoxynivalenol (vomitoxin) in mice. Int Orthop 2001, 25, 194-198.

9. Desheng Q., Fan L, Yanhu Y., Niya Z.: Adsorption of aflatoxin $\mathrm{B}_{1}$ on montmorillonite. Poult Sci 2005, 84, 959-961.

10. Dumont E.R.: Bone density and the lightweight skeletons of birds. Proc Royal Soc B Biol Sci 2010, 277, 2193-2198.

11. EFSA European Food Safety Authority Panel on Additives and Products or Substances used in Animal Feed (FEEDAP); Scientific Opinion on the safety and efficacy of bentonite (dioctahedral montmorillonite) as feed additive for all species. EFSA J 2011, 9, 2007. doi:10.2903/j.efsa.2011.2007.

12. The European Communities Council Directive $98 / 58 / \mathrm{EC}$ of 20 July 1998 concerning the protection of animals kept for farming.

13. Ferretti J.L., Capozza R.F., Mondelo N., Zanchetta J.R.: Interrelationships between densitometric, geometric and mechanical properties of rat femora: inferences concerning mechanical regulation of bone modelling. J Bone Min Res 1993, 8, 1395-1399.

14. Huff W.E., Doerr J.A., Hamilton P.B., Hamann D.D., Peterson R.E., Ciegler A.: Evaluation of bone strength during aflatoxicosis and ochratoxicosis. Appl Environ Microbiol 1980, 40, 102-107.

15. Lake B.G., Phillips J.C., Walters D.G., Bayley D.L., Cook M.W., Thomas L.V., Gilbert J., Startin J.R., Baldwin N.C.P., Bycroft B.W., Dewick P.M. Studies on the metabolism of deoxynivalenol in the rat. Food Chem Toxicol 1987, 25, 589-592.

16. Lee Y.M., Fujikado N., Manaka H., Yasuda H., Iwakura Y. IL-1 plays an important role in the bone metabolism under physiological conditions. Int Immunol 2010, 22, 805-816.

17. Lievers W.B., Lee V., Arsenault S.M., Waldman S.D., Pilkey A.K.: Specimen size effect in the volumetric shrinkage of cancellous bone measured at two level of dehydration. J Biomech 2007, 40, 1903-1909. 
18. Mastromatteo M., Conte A., Del Nobile M.A.: Combined use of modified atmosphere packaging and natural compounds for food preservation. Food Eng Rev 2010, 2, 28-38.

19. Pestka J.J.: Deoxynivalenol: Toxicity, mechanisms and animal health risks. Anim Feed Sci Technol 2007, 137, 283-298.

20. Prelusky D.B., Gerdes R.G., Underhill K.L., Rotter B.A., Jui P.Y., Trenholm H.L.: Effects of low-level dietary deoxynivalenol on haematological and clinical parameters of the pig. Nat Toxins 1994, 2, 97-104.

21. Saltman P.D., Strause L.G.: The role of trace minerals in osteoporosis. J Am College Nutr 1993, 12, 384-389.

22. Sergeev I.N., Kravchenko L.V., Piliia N.M., Batukhanov A.B., Sobolev V.S., Kuzmina E.E., Iakushina L.M., Spirichev V.B., Tutelian V.A.: The effect of trichotecene mycotoxin deoxynivalenol (vomitoxin) on calcium homeostasis, vitamin D metabolism and receptors in the rats. Vop Med Khim 1990, 36, 26-29.
23. Slanina L.: Buffering of the rumen contents by montmorillonite in cattle kept under industrial conditions. Dtsch Tierarztl Wochenschr 1974, 81, 552-555.

24. Śliwa E.: 2-Oxoglutaric acid administration diminishes fundectomy-induced osteopenia in pigs. J Anim Physiol Anim Nutr (Berl) 2010, 94, 86-95.

25. Tomaszewska E., Dobrowolski P., Siwicki A.K.: Maternal treatment with dexamethasone at minimal therapeutic doses inhibits neonatal bone development in a gender-dependent manner. Livest Sci 2012, 146, 175-182.

26. Tomaszewska E., Dobrowolski P., Kostro K., Jakubczak A., Taszkun I., Jaworska-Adamu J., Żmuda A., Rycerz K., Muszyński S.: The effect of HMB and 2-Ox administered during pregnancy on bone properties in primiparous and multiparous minks (Neivison vison). Bull Vet Inst Pulawy 2015, 59, 563-568. 